\title{
Technologia ultraszybkiego napawania laserowego do nakładania powłok funkcjonalnych Stellite 6 w branży lotniczej
}

\author{
Ultra-High Speed Laser Cladding (UHSLC) technology \\ for Stellite 6 functional coatings deposition in aviation industry
}

\section{Streszczenie}

Technologia ultraszybkiego napawania laserowego stanowi rozwinięcie metod deponowania powłok funkcjonalnych przy użyciu wiązki lasera. Charakteryzuje się ona wysokimi prędkościami procesu, pozwalając uzyskiwać znaczne szybkości chłodzenia oraz niewielkie wymieszanie z podłożem, co prowadzi do dużej czystości materiału powłoki i lepszych własności nałożonej warstwy w porównaniu z konwencjonalnym napawaniem laserowym. W niniejszym artykule przedstawiono technologię ultraszybkiego napawania laserowego w aplikacji dla przemysłu lotniczego. Zaprezentowano opracowane stanowisko do realizacji procesu oraz weryfikację technologii na komponencie podwozia samolotu, modyfikowanym w ramach projektu AMpHOra. Uzyskane rezultaty wskazują, że otrzymane tą technologią powłoki mogą stanowić alternatywę względem powłok elektrolitycznych z twardego chromu.

Słowa kluczowe: napawanie laserowe; powłoki funkcjonalne; lotnictwo

\begin{abstract}
Ultra-High-Speed Laser Cladding technology is one of the developments of functional coating deposition methods with usage of laser beam. It is characterized by high cladding velocities, allowing to obtain a significant cooling rates and low dilution, which leads to high purity of the clad and thus increase of properties of the deposited coating in comparison with the conventional laser cladding. In this paper a technology of Ultra-High-Speed Laser Cladding has been shown in case of applications for the aviation industry. The developed setup for the process has been presented and verification of the technology on the airplane chassis component for AMpHOra project has been discussed. The obtained results shown indicate that the coating received via this technology may compete with hard chrome plating.
\end{abstract}

Keywords: laser cladding; functional coatings; aviation

\section{Wstęp}

Od części lotniczych wymaga się wysokich własności mechanicznych, odporności korozyjnej przy zachowaniu niewielkiego ciężaru właściwego komponentu. Wymusza to $w$ wielu wypadkach stosowanie powłok ochronnych, podwyższających odporność na zużycie ścierne czy oddziaływanie czynników korozyjnych. Powszechnie stosowaną powłoką jest twardy chrom nakładany elektrolitycznie, który jednak zgodnie z rozporządzeniem Parlamentu Europejskiego nr 1907/2006 (REACH) trafił na listę substancji o ograniczonej dystrybucji. Jednym ze sposobów zastąpienia powłoki chromowej jest zastosowanie technologii natryskiwania lub napawania stopów niklu oraz kobaltu z dodatkiem chromu.
W przypadku rozpatrywanego w tym artykule stopu Co-Cr-W-C (Stellite 6) wykorzystywanych jest wiele metod nanoszenia powłok tj. natryskiwanie termiczne, plazmowe, HVOF oraz napawanie laserowe. Badania porównawcze przedstawione w pracy [1] pokazują, iż technologia napawania laserowego pozwala na uzyskanie powłoki Stellite 6 o największej twardości i odporności na zużycie ścierne w próbie pin-on disc.

Napawanie laserowe stanowi jedną z nowoczesnych i wciąż rozwijających się metod wytwarzania powłok funkcjonalnych. Pozwala na uzyskiwanie warstw o składzie chemicznym i własnościach znacznie różniących się od materiału

Mgr inż. Piotr Koruba, mgr inż. Piotr Jurewicz, dr hab. inż. Jacek Reiner - Politechnika Wrocławska, mgr inż. Adam Dworak, mgr inż. Janusz Mądry - Polskie Zakłady Lotnicze Mielec.

Autor korespondencyjny/Corresponding author: piotr.koruba@pwr.edu.pl 
podłoża [2]. Dzięki możliwości wykonywania powłok napawanych laserowo o grubości nawet rzędu 50 $\div 100 \mu \mathrm{m}$,

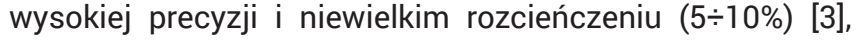
technologia ta może stanowić alternatywę do chromowania elektrolitycznego, operacji powszechnej w produkcji części stalowych w branży lotniczej. W przypadku napawania laserowego zauważa się jednak negatywny wpływ rozcieńczenia warstwy napawanej przez materiał podłoża na jej własności.

Jednym z działań, dzięki któremu można podwyższyć odporność na zużycie ścierne jest wykonanie powłoki kompozytowej [5], gdzie Stellite 6 stanowi jedynie osnowę napawanej warstwy, natomiast fazą odpowiedzialną za podwyższenie własności ściernych jest węglik B4C. Znacznie mniej kosztownym sposobem wpływania na własności warstwy napawanej jest przedstawione w [6] sterowanie rozmiarem mikrostruktury przy pomocy prędkości chłodzenia, na którą wpływa jeden z głównych parametrów procesu tj. prędkość napawania, przy czym istotny jest występujący w materiale mechanizm umocnienia. W przypadku stopu Stellite 6 zwiększenie prędkości napawania powoduje znaczne rozdrobnienie ziarna [7], co jest spowodowane zmniejszeniem odległości odgałęzień dendrytów drugiego rzędu.

Przedstawioną w niniejszej pracy technologię ultraszybkiego napawania laserowego (UHSLC) należy uznać za rozwinięcie konwencjonalnego napawania laserowego. Po raz pierwszy opisana została ona w pracy [8], gdzie jako materiału dodatkowego użyto stopu Inconel 625. Obecnie ma ona zastosowanie komercyjne, jednakże brak jest wyników badań tego procesu i jego rezultatów. W ramach niniejszego artykułu przedstawiono wyniki ultraszybkiego napawania laserowego do wytwarzania powłok ze stopu Stellite 6. Uzyskane rezultaty wskazują, że UHSLC może stanowić alternatywę dla chromowania elektrolitycznego w przypadku komponentów z branży lotniczej.

\section{Technologia UHSLC}

W przypadku technologii UHSLC główną cechą charakterystyczną procesu jest zastosowanie bardzo wysokich prędkości względnego ruchu wiązki i przedmiotu napawanego, sięgających nawet $200 \mathrm{~m} / \mathrm{min}$ [8]. Uzyskanie prawidłowego przetopu materiału, przy zmniejszonej energii liniowej, realizowane jest poprzez modyfikację wzajemnego pozycjonowania kaustyki strumienia proszku i kaustyki wiązki laserowej, w taki sposób, aby materiał dodatkowy ulegał częściowemu nadtopieniu przed kontaktem z podłożem (rys. 1). Zwiększenie szybkości procesu, poza oczywistym

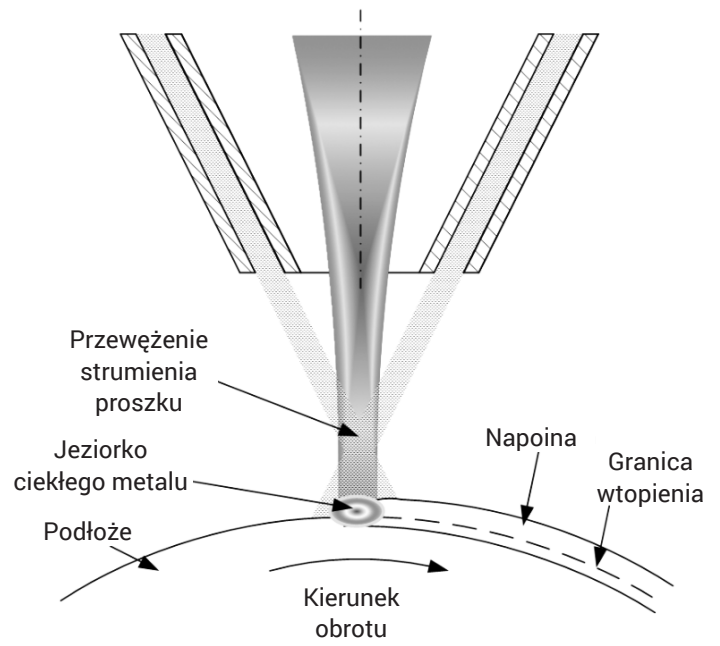

Rys. 1. Schemat procesu ultraszybkiego napawania laserowego (UHSLC)

Fig. 1. Scheme of Ultra High-Speed Laser Cladding process (UHSLC) wzrostem wydajności napawania bardzo istotnie wpływa na prędkości chłodzenia nakładanego materiału, co skutkuje powstawaniem drobniejszej mikrostruktury oraz wzrostem twardości.

Ponadto obserwowane są również mniejsze wartości rozcieńczenia napoiny sięgające maksymalnie $5 \%$, dzięki czemu wzrasta czystość metalurgiczna wytwarzanych powłok.

\section{Materiały do badań}

Wytypowanym elementem do badań procesu UHSLC był uproszczony geometrycznie komponent podwozia samolotu w postaci tulei o średnicy zewnętrznej $84 \mathrm{~mm}$, z materiału AISI 4330, wg norm amerykańskich. Jest to stal niskostopowa z dodatkiem niklu, chromu oraz wanadu, przeznaczona do ulepszania cieplnego (tabl. I).

Tablica I. Skład chemiczny podłoża - stali AISI 4330 [9]

Table I. The chemical composition of the substrate - steel AISI 4330 [9]

\begin{tabular}{|c|c|c|c|c|c|c|c|}
\hline \multirow{2}{*}{$\begin{array}{c}\text { Nazwa } \\
\text { materiału }\end{array}$} & \multicolumn{7}{|c|}{ Skład chemiczny [\% wag.] } \\
\cline { 2 - 8 } & $\mathrm{Fe}$ & $\mathrm{Ni}$ & $\mathrm{Mn}$ & $\mathrm{Si}$ & $\mathrm{Cr}$ & $\mathrm{Mo}$ & $\mathrm{C}$ \\
\hline AISI 4330 & $\begin{array}{c}95,3 \\
\div 98,1\end{array}$ & $\begin{array}{c}1,0 \\
\div 1,5\end{array}$ & $\leq 1,0$ & $\leq 0,8$ & $\begin{array}{c}0,4 \\
\div 0,6\end{array}$ & $\begin{array}{c}0,3 \\
\div 0,5\end{array}$ & $\begin{array}{c}0,2 \\
\div 0,3\end{array}$ \\
\hline
\end{tabular}

Rozpatrywanym materiałem dodatkowym był otrzymywany przez atomizację gazową sferoidalny proszek MetcoClad 6F o składzie chemicznym zbliżonym do stopu Stellite 6 (tabl. II). Oznaczenie 6F wskazuje, że frakcja rozmiaru ziaren proszku mieści się w zakresie $20 \div 53 \mu \mathrm{m}$.

Tablica II. Skład chemiczny materiału dodatkowego - proszku MetcoClad 6F [10]

Table II. The chemical composition of additional material - powder MetcoClad 6F [10]

\begin{tabular}{|c|c|c|c|c|c|c|c|}
\hline \multirow{2}{*}{$\begin{array}{c}\text { Nazwa } \\
\text { materiału }\end{array}$} & \multicolumn{7}{|c|}{ Skład chemiczny [\% wag.] } \\
\cline { 2 - 8 } & Co & Cr & W & C & Si & Fe & Inne \\
\hline $\begin{array}{c}\text { Metco- } \\
\text { Clad 6F }\end{array}$ & $\begin{array}{c}55,0 \\
\div 64,0\end{array}$ & $\begin{array}{c}26,0 \\
\div 30,0\end{array}$ & $\begin{array}{c}3,5 \\
\div 5,5\end{array}$ & $\begin{array}{c}1,0 \\
\div 1,3\end{array}$ & $\begin{array}{c}1,2 \\
\div 3,0\end{array}$ & $\leq 3,0$ & $<1$ \\
\hline
\end{tabular}

\section{Opracowane stanowisko do badań}

Stanowisko do ultraszybkiego napawania (UHSLC) opracowano jako rozszerzenie zrobotyzowanego stanowiska do napawania laserowego. W jego skład wchodzą następujące komponenty (rys. 2):

- robot przemysłowy 6-cio osiowy - REIS RV60-40,

- tokarka uniwersalna erba Compact 300 (rys. 3),

- mikroprocesorowy układ regulacji prędkości obrotowej wrzeciona,

- laser półprzewodnikowy Laserline 4000 z głowicą do napawania COAXpowerline,

- podajnik proszku GTV H-PF2/2. 


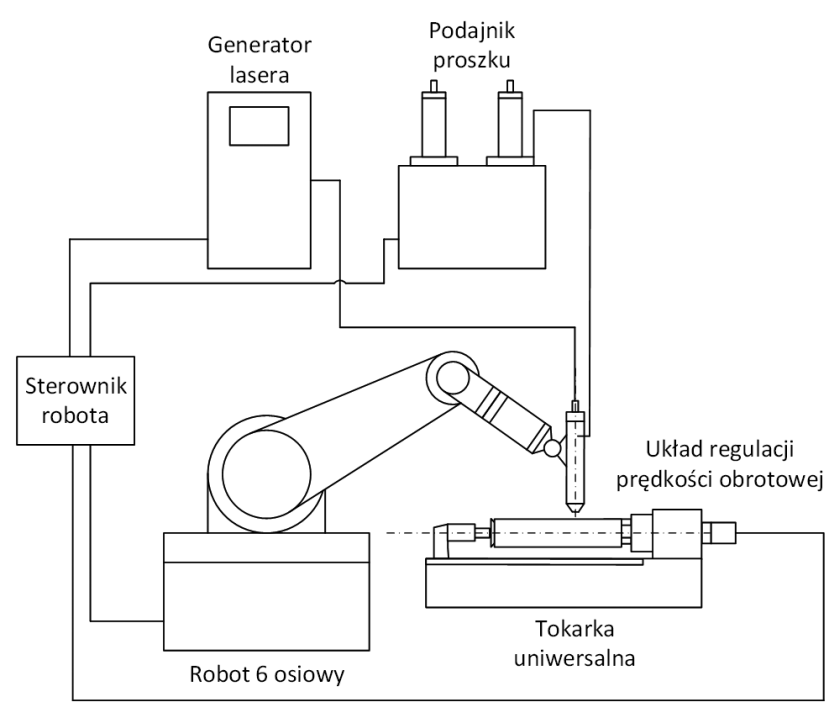

Rys. 2. Schemat stanowiska do realizacji procesu UHSLC

Fig. 2. Scheme of research station for UHSLC process realization

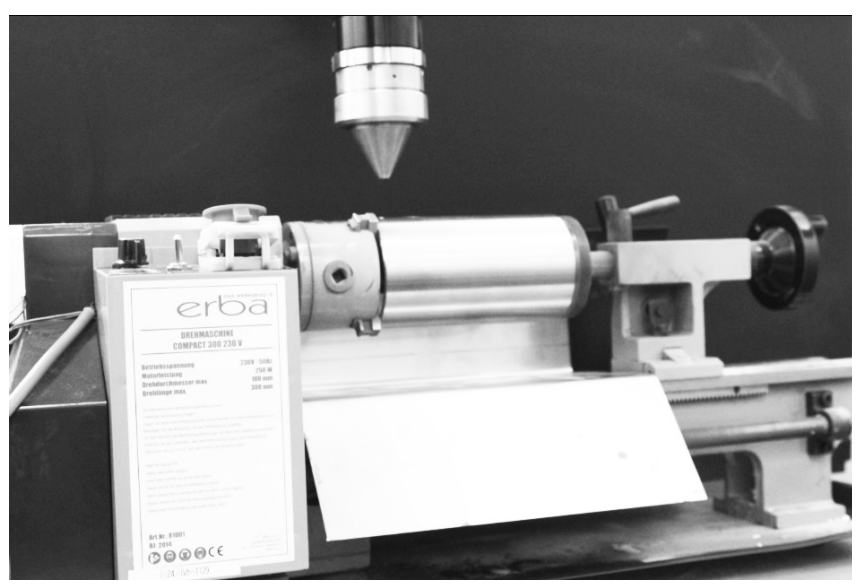

Rys. 3. Zdjęcia stanowiska do realizacji procesu UHSLC

Fig. 3. Research station for UHSLC process realization

Proces ultraszybkiego napawania na opracowanym stanowisku sterowany jest aktualnie poprzez sterownik robota. W pierwszej kolejności zadawana jest prędkość obrotowa wrzeciona tokarki, którą stabilizuje opracowany mikroprocesorowy układ regulacji. Na podstawie prędkości obrotowej wyznaczana jest prędkość obwodowa elementu napawanego:

$$
\mathrm{V}_{\mathrm{obw}}=\pi \mathrm{dn} / 1000
$$

gdzie:

vobw - prędkość obwodowa [m/min],

$\mathrm{d}$ - średnica przedmiotu napawanego [mm],

$\mathrm{n}$ - prędkość obrotowa wrzeciona [obr/min].

Po osiągnięciu zadanej prędkości obrotowej uruchamiany jest najazd głowicy napawającej na pozycję początkową oraz podawanie materiału dodatkowego i gazu osłonowego. Po potwierdzeniu poprawności ustawienia głowicy sterownik w trybie automatycznym uruchamia generowanie wiązki laserowej i zaczyna ruch liniowy z zadaną prędkością wzdłuż osi obrotu elementu (oś Z tokarki). Do obliczenia prędkości liniowej głowicy laserowej posłużono się następującym równaniem:

$$
\mathrm{V}_{\text {lin }}=\left((1-0) \cdot \mathrm{d}_{\text {las }} \cdot \mathrm{n}\right) / 60
$$

gdzie:

$\mathrm{V}_{\text {lin }}$ - prędkość liniowa [mm/s], o - współczynnik nałożenia kolejnych napoin [0-1],

$\mathrm{d}_{\text {las }}$ - średnica plamki lasera [mm].

Prędkość napawania stanowi wypadkową obu obliczonych prędkości, przy czym zwykle $v_{\text {lin }}<<v_{\text {obw }}$, co pozwala zastosować następujące uproszczenie przy doborze prędkości obrotowej wrzeciona tokarki:

$$
\mathrm{V}=\sqrt{\left(\mathrm{v}_{\mathrm{obw}}{ }^{2}+\mathrm{V}_{\text {lin }}{ }^{2}\right)} \cong \mathrm{v}_{\mathrm{obw}}
$$

Prędkość przyjęta do realizacji prób napawania na stanowisku wynosiła $50 \mathrm{~m} / \mathrm{min}$. Ruch wzdłuż osi elementu z aktywną wiązką lasera powtarzany jest zadaną przez użytkownika liczbę cykli. Po wykonaniu wszystkich warstw sterownik robota automatycznie wyłącza podawanie materiału dodatkowego i gazu osłonowego.

\section{Przebieg procesu i weryfikacja działania}

W ramach weryfikacji procesu ultraszybkiego napawania laserowego przeprowadzono próby napawania proszkiem MetcoClad 6F. Wykonane powłoki testowe miały szerokość $12 \mathrm{~mm}$. Skonfigurowano tor optyczny kształtowania wiązki laserowej, w taki sposób, aby uzyskać plamkę w ognisku o średnicy 1,5 mm, natomiast współczynnik nałożenia napoin przyjęto równy 0,5. Między wykonywaniem kolejnych przejazdów głowicy stosowano przystanki czasowe (5 sekund), których zadaniem było umożliwienie wyrównania się temperatury wcześniej nałożonych warstw. Rysunek 4 przedstawia rezultaty ultraszybkiego napawania laserowego materiału Stellite 6 na podłożu ze stali ulepszonej cieplnie AISI 4330. Powłoki różniły się liczbą warstw nałożonego materiału dodatkowego, przy czym szybkość podawania proszku wynosiła 36,8 g/min. Natomiast gęstość mocy zdefiniowana jako iloraz mocy i powierzchni plamki lasera $(\Phi)$ oraz energia liniowa $\left(E_{\text {lin }}\right)$ były stałe i wynosiły odpowiednio $\Phi-1,7 \cdot 10^{5} \mathrm{~W} / \mathrm{cm}^{2}$ i $\mathrm{E}_{\text {lin }}-3,6 \cdot 10^{-3} \mathrm{~kJ} / \mathrm{mm}$.

\section{a)}

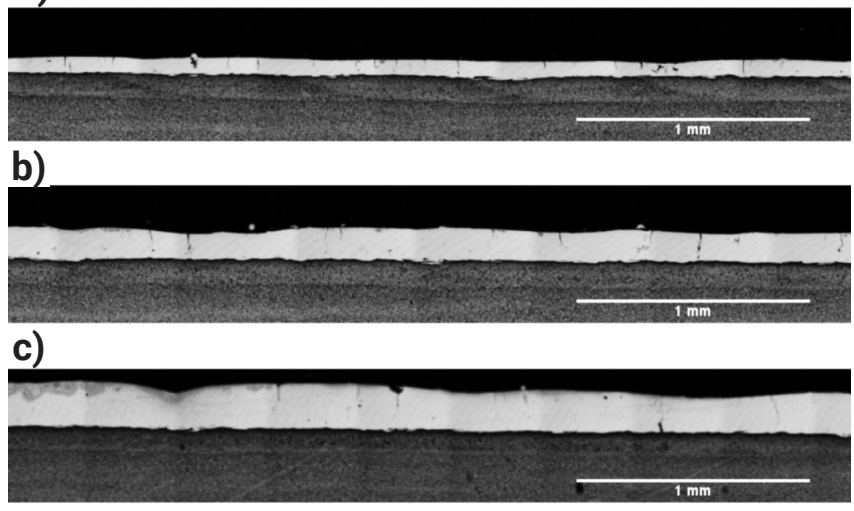

Rys. 4. Zgłady metalograficzne powłok napawanych laserowo Stellitem 6 uzyskanych w procesie UHSLC: a) 5 warstw, b) 10 warstw, c) 15 warstw

Fig. 4. Cross-sectional microstructure of laser deposited Stellite 6 coatings received in UHSLC process: a) 5 layers, b) 10 layers, c) 15 layers

Parametry otrzymanych powłok zebrano w tablicy III. Wysokość napawanej powłoki rośnie proporcjonalnie do liczby warstw, przy czym można przyjąć, iż wysokość pojedynczej warstwy wynosi ok. $13 \mu \mathrm{m}$. Zmierzona mikrotwardość HV 0,1 powłok wg tablicy III również wykazuje zmienność. Zauważalny jest wzrost wartości średniej z serii pomiarów oraz zmniejszanie się dyspersji wyników wraz ze wzrostem liczby warstw (rys. 5). 
Tablica III. Własności geometryczne i mikrotwardość powłok otrzymanych w procesie UHSLC

Table III. Geometric properties and microhardness of coatings obtained in UHSLC process

\begin{tabular}{|c|c|c|c|c|}
\hline $\begin{array}{c}\text { Ilość } \\
\text { warstw } \\
\text { Stellite 6 }\end{array}$ & $\begin{array}{c}\text { Wysokość } \\
\text { napoiny } \\
{[\mu \mathrm{m}]}\end{array}$ & $\begin{array}{c}\text { Rozstęp } \\
\text { wysokości } \\
{[\mu \mathrm{m}]}\end{array}$ & $\begin{array}{c}\text { Głębokość } \\
\text { SWC } \\
{[\mu \mathrm{m}]}\end{array}$ & $\begin{array}{c}\text { Mikrotwar- } \\
\text { dość } \\
\text { HV 0,1 }\end{array}$ \\
\hline 5 & 67 & 50 & 110 & 561 \\
\hline 10 & 131 & 35 & 129 & 640 \\
\hline 15 & 198 & 51 & 112 & 678 \\
\hline
\end{tabular}

Z przeprowadzonych pomiarów geometrii napoin w przekroju poprzecznym wynika również, że głębokość SWC w przypadku wszystkich trzech powłok jest porównywalna i mieści się w przedziale 110 $\div 130 \mu \mathrm{m}$.

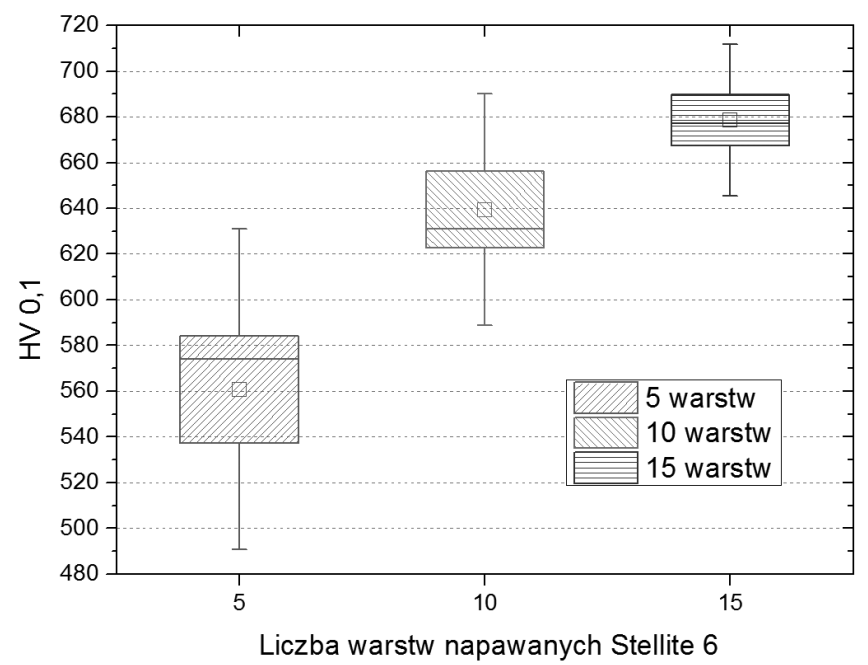

Rys. 5. Rozkład mikrotwardości HV 0,1 powłok napawanych w procesie UHSLC

Fig. 5. Microhardness HV 0.1 distribution of coatings obtained in UHSLC process

W przypadku wszystkich wytworzonych powłok zauważono jednak występowanie pęknięć, które wraz ze wzrostem liczby warstw napawanych zaczynały się znacznie rozrastać w charakterystyczne kratery. Przekrój poprzeczny napoiny wykazuje ponadto, że część z nich propaguje na całej grubości powłoki, czyniąc ją nieszczelną (rys. 4b). Celem uniknięcia pęknięć powłok, zwiększono energię liniową poprzez redukcję prędkości napawania do $20 \mathrm{~m} / \mathrm{min}$. Na rysunku 6 przedstawiono przekrój poprzeczny otrzymanej tym sposobem powłoki złożonej z 3 warstw $\left(\Phi-1,4 \cdot 10^{5} \mathrm{~W} / \mathrm{cm}^{2}, \mathrm{E}_{\text {lin }}-7,5 \cdot 10^{-3} \mathrm{~kJ} / \mathrm{mm}\right)$.

Wynik badań nieniszczących PT oraz zdjęcia zgładu metalograficznego przekroju poprzecznego napoiny nie ujawniły występowania pęknięć. Należy podkreślić, iż w przypadku

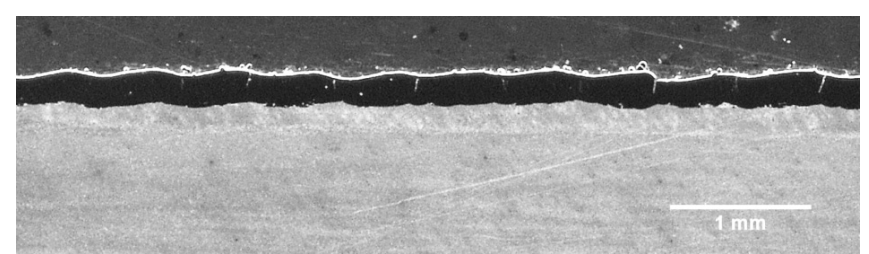

Rys. 6. Zgład metalograficzny powłoki Stellite 6 bez pęknięć uzyskana w procesie UHSLC

Fig. 6. Cross-sectional microstructure of Stellite 6 coating without cracks received in UHSLC process

powłoki ukazanej na rysunku 6 zastosowano również większy współczynnik nałożenia napoin równy 0,6, aby zmniejszyć charakterystyczny dla procesu rozrzut wysokości napoiny.

\section{Porównanie z konwencjonalnym napawaniem laserowym}

Wyniki technologii ultraszybkiego napawania laserowego porównano z konwencjonalnym procesem napawania laserowego. W obu przypadkach napawano powłoki Stellite 6 na tulei ze stali AISI 4330 na długości 120 mm w przypadku napawania konwencjonalnego (LC) oraz $160 \mathrm{~mm}$ (UHSLC). Na rysunku 7 przedstawiono rezultaty napawania laserowego w obu procesach.

llościowe porównanie rezultatów obu procesów zestawiono w tablicy IV. Należy zauważyć, że w procesie UHSLC otrzymano powłokę o porównywalnej wysokości, pozbawioną wad powierzchniowych, lecz o wyższej mikrotwardości oraz mniejszej SWC.
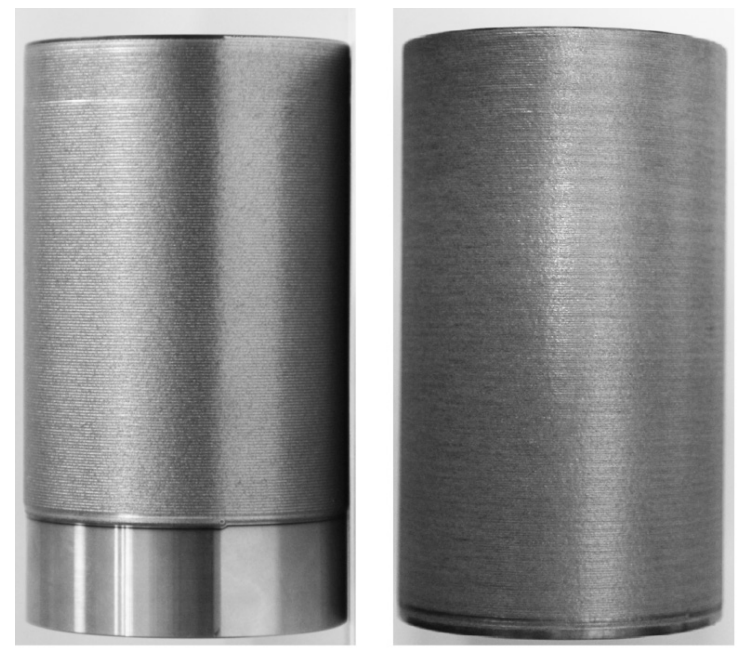

Rys. 7. Tuleja ze stali AISI 4330 napawana Stellitem 6: a) konwencjonalnie, b) w procesie UHSLC

Fig. 7. AISI 4330 steel bush cladded with Stellite 6: a) conventionally, b) in UHSLC process

Tablica IV. Porównanie powłok otrzymanych w procesach LC oraz UHSLC

Table IV. Comparison of laser deposited coating in LC and UHSLC processes

\begin{tabular}{|c|c|c|c|c|c|c|}
\hline Proces & $\begin{array}{l}\text { Czas procesu } \\
\text { [min] }\end{array}$ & $\begin{array}{c}\text { Głębokość SWC } \\
{[\mu \mathrm{m}]}\end{array}$ & $\begin{array}{c}\text { Wysokość } \\
\text { napoiny [ }[\mu \mathrm{m}]\end{array}$ & HV 0,1 & Liczba warstw & Pęknięcia \\
\hline LC & 75 & 690 & 227 & $\sim 550$ & 1 & brak \\
\hline UHSLC & 15 & 288 & 199 & $\sim 800$ & 3 & brak \\
\hline
\end{tabular}




\section{Wnioski}

Technologia ultraszybkiego napawania laserowego znacznie podnosi własności powłok napawanych w porównaniu z jej konwencjonalną realizacją. W przypadku zastosowanego materiału Stellite 6 możliwe jest otrzymanie warstwy napawanej bez wad powierzchniowych, charakteryzującej się twardością na poziomie 800 HV. Ponadto istnieje możliwość sterowania twardością powłoki przez liczbę nałożonych cienkich warstw materiału dodatkowego.

Z punktu widzenia zagadnienia ekonomiczności proces UHSLC skraca również kilkukrotnie czas główny napawania, przy czym wykonana powłoka jest wielowarstwowa. Należy jednak zaznaczyć, że zbytnie obniżenie energii liniowej napawania może powodować powstawanie pęknięć krystalizacyjnych. Rozmiar strefy wpływu ciepła w porównaniu z konwencjonalnym napawaniem laserowym również ulega zmniejszeniu nawet do głębokości $100 \mu \mathrm{m}$.

Powyższe rezultaty pozwalają stwierdzić, że technologia UHSLC stanowi obiecującą metodę wytwarzania powłok funkcjonalnych komponentów dla branży lotniczej.

Badania realizowane w ramach projektu sektorowego INNOLOT (Akronim AMpHOra) pt. „Badania technologii przyrostowych procesów hybrydyzacji obróbki dla potrzeb rozwoju innowacyjnej produkcji lotniczej", koordynowanego przez Polskie Zakłady Lotnicze Sp. z o.o. - PZL Mielec, współfinansowanego ze środków Narodowego Centrum Badań i Rozwoju oraz Unii Europejskiej w ramach Europejskiego Funduszu Rozwoju Regionalnego w zakresie Programu Operacyjnego Innowacyjna Gospodarka Priorytet l., Działanie 1.5 PO IG., nr umowy INNOLOT /I/6/NCBR/2013

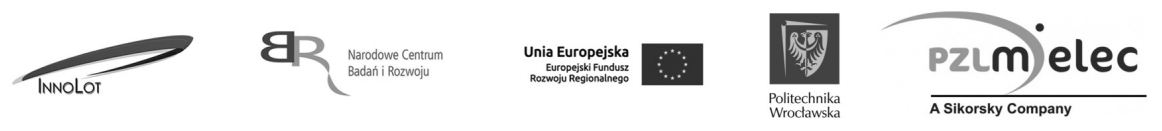

\section{Literatura}

[1] A. Kusmoko, D. Dunne, H. Li: A Comparative Study for Wear Resistant of Stellite 6 Coatings on Nickel Alloy Substrate Produced by Laser Cladding, HVOF and Plasma Spraying Techniques, International Journal of Current Engineering and Technology, vol. 4, nr 1, pp.3236, 2014.

[2] A. Borek, R. Grzelka, A. Klimpel i in.: Technologie laserowe spawania, wytwarzania i obróbki cieplnej warstw wierzchnich, Przegląd Spawalnictwa, vol. 85, nr 10, s. 10-18, 2013.

[3] T. Baraniecki, E. Chlebus, M. Dziatkiewicz i in.: System laserowego mikronapawania proszków metali, Przegląd Spawalnictwa, vol. 83, nr 9, s. 22-26, 2011.

[4] G. Kinal, D. Bartkowski, A. Piasecki i in.: Laserowe napawanie kompozytowych warstw powierzchniowych Stellite-6/B4C, Inżynieria Materiałowa, vol. 35, nr 5, s. 382-385, 2014.

[5] V. Ocelik, I. Hemmati, Th. M. De Hosson: The Influence Of Processing Speed On The Properties Of Laser Surface Deposits, Surface Effects and Contact Mechanics including Tribology XII, vol. 91, s. 93-103, 2015.
[6] A. Frenk, W. Kurz: High speed laser cladding: solidification conditions and microstructure of a cobalt-based alloy, Materials and Science Engineering, vol. 173, nr 1-2, s. 339-342, 1993.

[7] G. A. Turichin, O. G. Klimova, E. V. Zemlyakov i in.: Technological aspects of high speed direct laser deposition based on heterophase powder metallurgy, Physics Procedia, vol. 78, s. 397-406, 2015.

[8] T. Schopphoven, A. Geasser, K. Wissenbach i in.: Investigations on ultrahigh-speed laser material deposition as alternative for hard chrome plating and thermal spraying, vol. 28, nr 2, 2016.

[9] AISI 4330 Alloy Steel (UNS J24045), materiały AZOM

[10] DSMW-0003.4 - CoCr Alloy Powders for Laser Cladding, dane firmy Oerlikon Metco. 